\title{
Robotic Surgery for Rectal Cancer and Cost-Effectiveness
}

\author{
Youngbae Jeon, M.D., Eun Jung Park, M.D., Ph.D., Seung Hyuk Baik, M.D., Ph.D., FASCRS \\ Division of Colon and Rectal Surgery, Department of Surgery, Gangnam Severance Hospital, Yonsei University College of Medicine, Seoul, Korea
}

Robotic surgery is considered as one of the advanced treatment modality of minimally invasive surgery for rectal cancer. Robotic rectal surgery has been performed for three decades and its application is gradually expanding along with technology development. It has several technical advantages which include magnified three-dimensional vision, better ergonomics, multiple articulated robotic instruments, and the opportunity to perform remote surgery. The technical benefits of robotic system can help to manipulate more meticulously during technical challenging procedures including total mesorectal excision in narrow pelvis, lateral pelvic node dissection, and intersphincteric resection. It is also reported that robotic rectal surgery have been shown more favorable postoperative functional outcomes. Despite its technical benefits, a majority of studies have been reported that there is rarely clinical or oncologic superiority of robotic surgery for rectal cancer compared to conventional laparoscopic surgery. In addition, robotic rectal surgery showed significantly higher costs than the standard method. Hence, the cost-effectiveness of robotic rectal surgery is still questionable. In order for robotic rectal surgery to further develop in the field of minimally invasive surgery, there should be an obvious cost-effective advantages over laparoscopic surgery, and it is crucial that large-scale prospective randomized trials are required. Positive competition of industries in correlation with technological development may gradually reduce the price of the robotic system, and it will be helpful to increase the cost-effectiveness of robotic rectal surgery.

Keywords: Rectal neoplasm, Robotic surgical procedures, Cost-benefit analysis

This is an Open Access article distributed under the terms of the Creative Commons Attribution Non-Commercial License (http:// creativecommons.org/licenses/by-nc/4.0/) which permits unrestricted non-commercial use, distribution, and reproduction in any medium, provided the original work is properly cited.
Received October 30, 2019

Revised November 27, 2019

Accepted November 28, 2019

Corresponding author

Seung Hyuk Baik

Division of Colon and Rectal

Surgery, Department of Surgery,

Gangnam Severance Hospital,

Yonsei University College of

Medicine, 20 Eonju-ro 63-gil,

Gangnam-gu, Seoul 06229, Korea

Tel: +82-2-2019-3378

Fax: +82-2-3462-5994

E-mail: whitenoja@yuhs.ac ORCID:

https://orcid.org/0000-0003-4183-2332
Copyright @ 2019 The Journal of Minimally Invasive Surgery. All rights reserved.

\section{INTRODUCTION}

Minimally invasive surgery has remarkably developed during the past decades, but, it is still challenging and needs a lot of technical demands. In the early 1990s, laparoscopic surgery appeared and has grown rapidly, then has been established as a standard method of minimally invasive surgery. ${ }^{1}$ According to several randomized studies, comparing open surgery, laparoscopic surgery has clinical benefits including smaller incisions, shorter hospital stay, and better postoperative recovery with comparable oncologic outcomes. ${ }^{2-4}$ Meanwhile, the robot- ic system provides magnified three-dimensional vision, better ergonomics, multiple articulated robotic instruments, and an opportunity to perform remote surgery. ${ }^{5}$ In terms of the advantage to approach narrow pelvic cavity, robotic surgery has been used prominently in the urologic and gynecologic fields. In recent, robotic rectal surgery including a robot-assisted laparoscopic approach or totally robotic surgery is increasing and regarded as an effective and surgeon-convenient treatment option that is suggested to overcome the limitations of laparoscopic surgery. ${ }^{6}$ Even though robotic surgery has those technical advantages, the cost-effectiveness of robot-assisted 
rectal surgery is still debatable. We herein reviewed the overview of robotic rectal surgery, and discussed in terms of costeffectiveness based on the literatures.

\section{DEVELOPMENT OF ROBOTIC SURGERY}

The surgical use of a robot in a machine has approximately 30 years of history. ${ }^{7}$ The first clinical use of a robot for surgery was the Automated Endoscopic System for Optimal Positioning (AESOP; Computer Motion Inc. Santa Barbara, CA), developed by Wang, in 1993. In the next year, AESOP was approved by the Food and Drug Administration (FDA) as an endoscopic camera manipulator. A few years later, the Zeus system (Computer Motion, Inc., Santa Barbara, CA) was invented with surgical arms and instruments, but it had a limited role as an assistant. After then, the da Vinci ${ }^{\circledR}$ system (Intuitive Surgical, Inc., Mountain View, CA) has been used in general surgery. Zeus system was decided to stop production in 2003, hence, the da Vinci ${ }^{\circledR}$ system is the only available surgical robot. ${ }^{8.9}$ Since Jacques Himpens and Gut Cardiere performed the first robot-assisted cholecystectomy in 1997, various general surgical procedures were performed with the da Vinci ${ }^{\circledR}$ system. ${ }^{7.10}$ In the early 2000s, Hashizume and Weber reported the first robotic colectomy for malignant and benign disease respectively. ${ }^{7,11,12}$ The first radical mesorectal excision of rectal cancer using the da Vinci ${ }^{\circledR}$ system was reported by Pigazzi et al. ${ }^{13}$ in 2006. Up to now, the da Vinci ${ }^{\oplus}$ system is developed Xi version with reduced docking time and improved image quality, and additionally, SP version for surgical access of narrow space.

\section{PROS AND CONS OF ROBOTIC RECTAL SURGERY}

Robotic rectal surgery has several benefits compared with conventional laparoscopic surgery. It offers magnified threedimensional view, hand-tremor filtering, fine dexterity with wrist articulation, surgeon comfort in console, and, assistantindependent operation of working arms and camera., ${ }^{5,14,15}$ The high resolution of the robotic visual system is helpful to preserve the pelvic autonomic nerve. ${ }^{16}$ Furthermore, better ergonomics and surgeon comfort design including sitting available at a console during surgery, and meticulous Endowrist ${ }^{\mathrm{TM}}$ (Intuitive Surgical, Sunnyvale, CA, USA) movement might reduce the fatigue of operator compared to conventional laparoscopic surgery. ${ }^{17}$ Especially, robotic total mesorectal excision (TME) has a potential benefit because of its technical difficulty to access the narrow pelvic cavity. ${ }^{13}$ Beak et al. ${ }^{16}$ reported that there was no significant difference among the easy, moderate, and difficult pelvic anatomy groups stratified by MRI-based pelvimetry, in terms of operation time and other perioperative outcomes for robotic TME. It implied that robotic approach can be comfortable to access narrow cavity, and it is more helpful to overcome difficulties regarding pelvic anatomy. In addition, several studies suggested that better recovery of urinary and sexual function in the robotic rectal surgery group comparing the laparoscopic rectal surgery group for the reason of more precise and meticulous dissection in robotic TME ${ }^{18-20}$ For the same reason, robotic system is regarded as a useful option when technically demanding procedures are required such as intersphincteric resection, or lateral pelvic lymph nodes. ${ }^{21-23}$

On the other hand, there is controversy regarding high cost, patient repositioning difficulty, complete loss of tactile feedback, and prolonged operative time., ${ }^{1,15,24,25}$ The docking procedure of the robotic cart is required more time and additional efforts. Furthermore, it is difficult to remove the robotic cart promptly, when an emergent open conversion is necessary, such as uncontrolled bleeding. Tactile feedback is useful during surgery, which provides numerous sensations when surgeons manipulate surgical procedures such as traction, palpation, grasping, pulling, and push of the structure, moreover, notification of tissue damage. Although technical development may improve the haptic feedback of the robotic surgical system, it does not yet provide the fine haptic feedback to the surgeon as accurately as the human touch sensation. ${ }^{26,27}$ The high cost is the main drawback of robotic surgery. The cost analysis is described at the bottom of the body text.

\section{LEARNING CURVE}

Although laparoscopic rectal surgery has been an alternative treatment of open surgery, in terms of surgeon's training, it requires a steeper learning curve than open surgery, because of its non-ergonomic surgical instruments and limited surgical view. ${ }^{28,29}$ The robotic surgical system provides better ergonomic tools, and high-resolution three-dimensional vision, therefore, it is expected that the learning curve is shorter than the laparoscopic procedure.

The learning curve of robotic rectal surgery was reported rage from 15 to 40 cases, ${ }^{30-35}$ whereas the value of laparoscopic rectal surgery was reported 30 to 70 cases. ${ }^{28,36,37}$ The learning curve of robotic surgery may be seen shorter than laparoscopic surgery, however, most studies have a single-arm design, and they have consisted of a small number of patients.

Park et al..$^{38}$ analyzed a single junior surgeon's learning curve of robotic TME for rectal cancer with 89 cases and compared them with the same size of conventional laparoscopic surgeries using the cumulative sum (CUSUM) method. In this study, the single surgeon started laparoscopic and robotic TME al- 
most simultaneously. The learning curve of robotic surgery for rectal cancer was 44 procedures and laparoscopic surgery was 41 procedures. According to the study, the learning curves between the two methods showed similar results with comparable clinicopathologic outcomes.

However, a majority of published studies did not consider the surgeon's prior experience of rectal surgery, which could affect the learning curve as a bias. Furthermore, the case complexity could be one of the influencing factors. Darcy et al. suggested that robotic rectal surgery may accelerate the learning curve when operating more complex cases compared with laparoscopic surgery because the perioperative outcomes were improved while case complexity increased. ${ }^{39}$ Therefore, the superiority of the learning curve between laparoscopy and robotic rectal surgery is controversial, and further studies should consider influencing factors that may cause bias.

\section{PERIOPERATIVE OUTCOMES}

It is established that robotic rectal surgery is safe and feasible compared to conventional minimally invasive surgery. Although the results in detail might vary depending on the studies, the recent comparative studies between laparoscopic and robotic TME for rectal cancer showed overall comparable clinical outcomes (Table 1). ${ }^{40-48}$ In 2008, Baik et al. ${ }^{40}$ reported a pilot randomized controlled study for comparing robotic and laparoscopic tumor-specific mesorectal excision (TSME) with a small population, the results showed that the mean operative time was not significantly different between the two groups (217.1 \pm 51.6 vs. $204.3 \pm 51.9, p=0.477)$. According to Park et al. $^{42}$ and Polat et al. ${ }^{48}$, the operative time also reported no difference. However, except for those studies, the other studies have shown that robotic rectal surgery not only showed longer operative time, ${ }^{43-47}$ but also shorter operative time ${ }^{41}$ than laparoscopic rectal surgery. Ramji et al. ${ }^{44}$ suggested that the learning curve and the familiarity of docking systems are the major factors of difference in operative time.

In terms of estimated blood loss (EBL) during operation, most of the studies reported that there was no significant difference between robotic and laparoscopic rectal surgery. According to Kim et al. ${ }^{46}$, the median EBL was higher in the robotic surgery group than in the laparoscopic surgery group (100 $\mathrm{mL}$ vs $50 \mathrm{~mL}, p<0.0001$ ), but, all the patients of both groups did not require blood transfusions.

The length of hospital stay (LOS) of robotic TME is generally similar or slightly shorter than laparoscopic surgery. ${ }^{40-48}$ Baik et al. ${ }^{40}$ presented the mean LOS of robotic rectal surgery was shorter than the laparoscopic approach (6.9 \pm 1.3 days vs 8.7 \pm 1.3 days, $p<0.001)$ in the short-term follow up. Park et al. ${ }^{42}$ also reported similar results regarding LOS in long-term fol- low up (5.86 \pm 1.43 days vs $6.54 \pm 2.65$ days, $p=0.035)$.

Regarding postoperative morbidity, robotic surgery has barely shown a significant difference compared to laparoscopic surgery. The complication rates of robotic TME were ranged from $14.3 \%$ to $47.6 \%$, while those of laparoscopic TME were ranged from $5.5 \%$ to $49.4 \% .^{40-48}$ Meanwhile, according to Baik et al. ${ }^{49}$, overall postoperative complication rates of both groups had no statistical difference (10.7 vs 19.3, $p=0.202$ ), but, the major complication rate of robotic low anterior resection were significantly lower than that of laparoscopic surgery (5.4 vs 19.3, $p=0.025$ ). This study suggested that the lower major complication rate in the robotic surgery group may be associated with a faster start of the diet and shorter length of hospital stay.

The range of conversion rate of robotic rectal surgery has been reported 0 to $12 \% .^{40-48}$ It is shown that the conversion rate of robotic TME had no statistical difference compared with laparoscopic TME, ${ }^{40,43-46}$ whereas, several studies suggested that robotic TME had a lower conversion rate than that of laparoscopic TME. ${ }^{41,42,48}$ According to the 'Robotic vs Laparoscopic Resection for Rectal Cancer (ROLARR)' randomized controlled trial which published the primary results at JAMA in 2017, there was no significant difference in conversion rates between robotic TME and conventional laparoscopic TME (8.1\% vs $12.2 \%, p=0.16){ }^{50}$ High body mass index and male affected open conversion rate because of its technical difficulty to manipulate in the limited abdomino-pelvic cavity. Furthermore, the significant lower conversion rate is reported in patients who underwent low anterior resection comparing with abdominoperineal resection, it is probably because that the major part of the oncological component is performed through the trans-perineal approach, not laparoscopic approach. ${ }^{50}$

\section{FUNCTIONAL OUTCOMES}

One of the potential benefits of robotic rectal cancer surgery is that it can lead better perioperative functional outcomes regarding voiding and sexual aspects. Pelvic autonomic nerve injury during TME procedure is a crucial cause of voiding and sexual dysfunction. The International Prostate Symptom Score (IPSS) and the International Index of Erectile Function (IIEF) questionnaires are generally used to assess urogenital dysfunction. According to a systematic review and meta-analysis, in ten studies including 689 patients which were evaluated the functional outcomes by IPSS and IIEF, robotic rectal surgery showed early improved urogenital function compared to laparoscopic rectal surgery. ${ }^{51}$ In recent, Wang et al. ${ }^{52}$ also reported that robotic rectal surgery showed less incidence of male urinary and sexual dysfunction. The postoperative 12 months total IPSS scores were significantly lower in robotic group than 


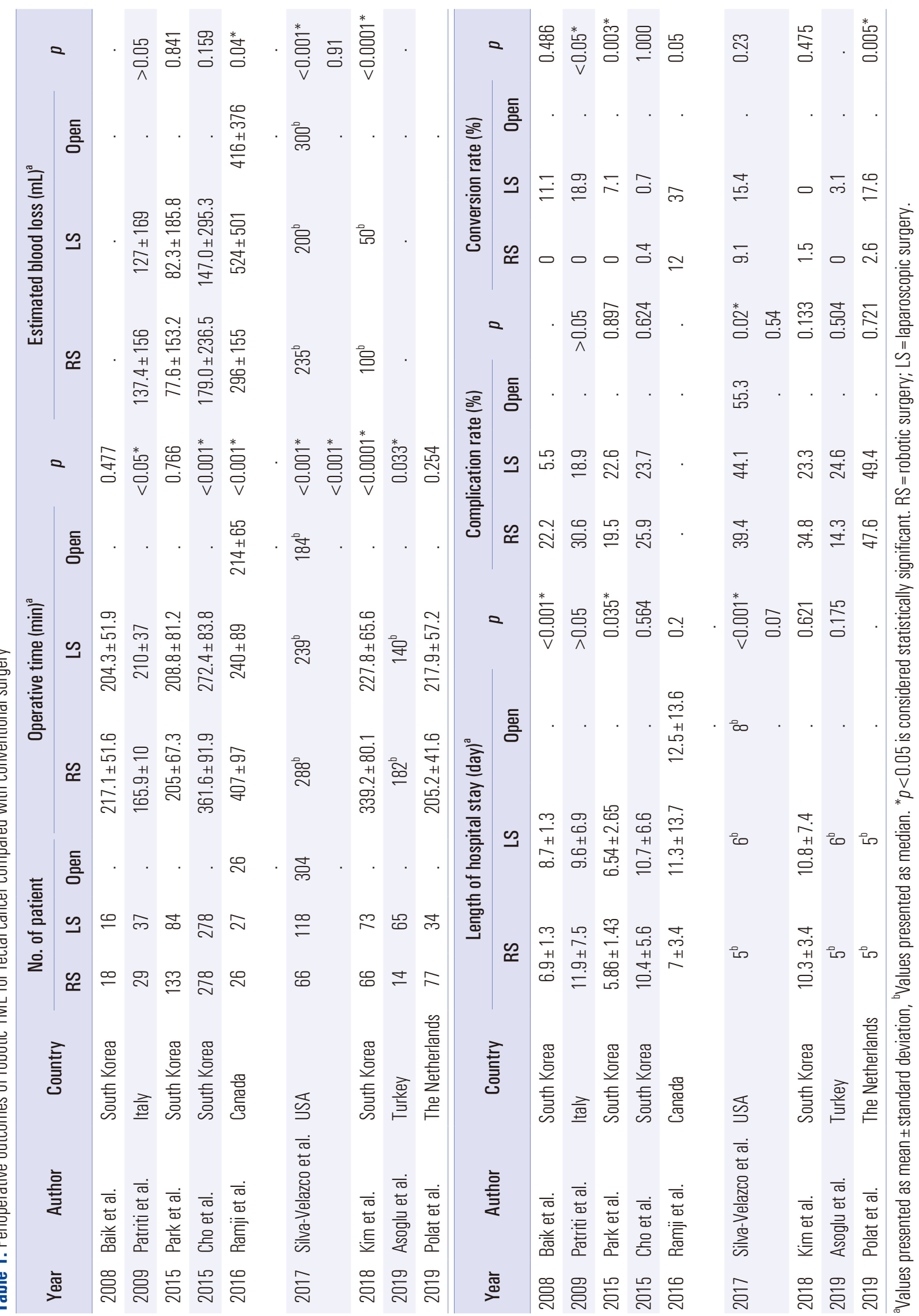




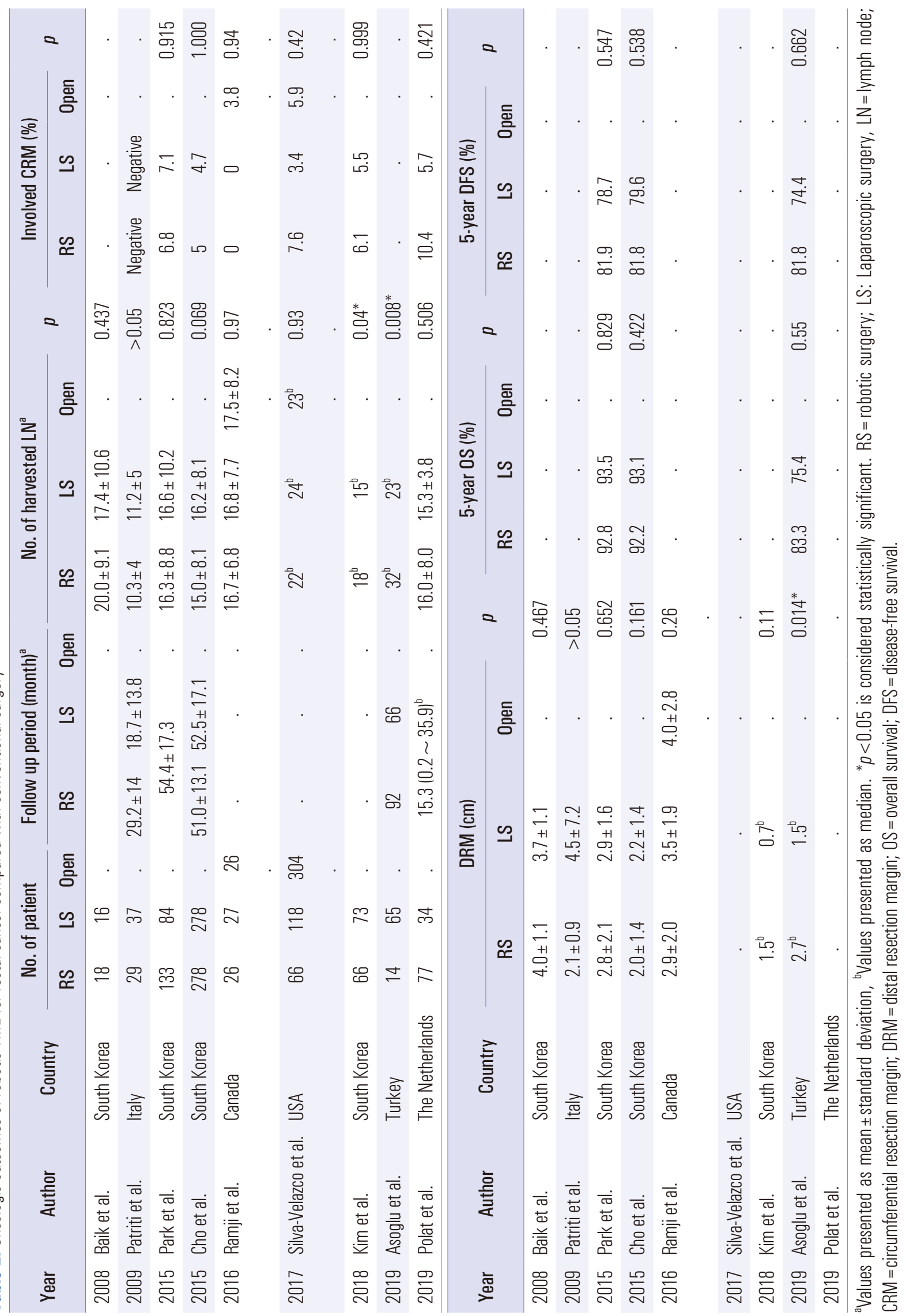


laparoscopic group (6.79 vs 9.66, $p=0.037$ ), and the postoperative 12 months total IIEF scores were significantly higher in robotic group than laparoscopic group (46.2 vs 40.1, $p=0.043$ ). It might be because the robotic system provides a clearer field of view and better ergonomics, therefore, they result in more meticulous manipulation for pelvic dissection comparing with laparoscopic approach. Robotic surgery seems to be more effective than laparoscopic surgery for pelvic autonomic nerve preservation in TME procedure, however, large-populated randomized trial is required.

\section{ONCOLOGIC OUTCOMES}

The oncologic outcomes of robotic TME are generally comparable to those of laparoscopic TME. Table 2 shows the oncologic outcomes of robotic TME for rectal cancer compared with conventional surgery in recently published studies, and there are rarely statistical differences between robotic TME and laparoscopic TME. ${ }^{40-48}$

The completeness of oncologic resection was reflected by the pathologic outcomes of the specimen including the number of harvested lymph nodes (LN), circumferential resection margin (CRM), and distal resection margin (DRM). The harvested LN of both groups were mostly more than 12 in the majority of studies. According to Kim et al. ${ }^{46}$ and Asoglu et $\mathrm{al}^{47}$, the number of harvested LN of the robotic group was statistically higher than that of the laparoscopic group (18 vs $15, p=0.04$, and 32 vs $23, p=0.008$ ), while a lot of other studies showed no significant difference. ${ }^{40-42,44,45,48}$ In terms of CRM involvement and the length of DRM, the results of both groups were also similar. Baik et al. ${ }^{49}$ compared completeness of the TME specimen between robotic and laparoscopic groups macroscopically, and the robotic group was superior to the laparoscopic group ( $p=0.033)$, hence, it might account for the technical advantage of the robotic system regarding more meticulous dissection. Nevertheless, the pathologic outcomes including harvested LN, CRM, and DRM showed no differences. $^{49}$

In short-term oncologic outcomes of robotic TME, the 3-year overall survival (OS), and 3-year disease-free survival (DFS) were ranged 90.1 97.0\%, and 73.7 79.2\%, respectively. ${ }^{49,53-58}$ Pai et al. ${ }^{54}$ reported that the local recurrence was $4 \%$ and the systemic recurrence was $17 \%$. Another study by Baek et al. ${ }^{53}$ reported that the local recurrence was $3.1 \%$ with the mean time of 23 months, and the systemic recurrence was 6.3\%. According to Feroci et al. ${ }^{59}$, comparing with laparoscopic TME, robotic TME did not show statistical difference regarding 3-year OS (robotic vs laparoscopic; $90.2 \%$ vs $90.0 \%$, $p=0.956)$, DFS (79.2\% vs $83.4 \%, p=0.268)$, local recurrence rate (1.9\% vs $5.2 \%, p=0.618$ ), and distant metastasis rate (17\% vs
$8.6 \%, p=0.256)$.

Park et al. ${ }^{42}$ reported the first article to compare the longterm oncologic outcomes between robotic and laparoscopic rectal surgery during the mean follow-up of 54.4 months. The 5-year OS (robotic vs laparoscopic; 92.8\% vs 93.5\%, $p=0.829$ ), DFS ( $81.9 \%$ vs $78.7 \%, p=0.547)$, and local recurrence rate $(2.3 \%$ vs $1.2 \%, p=0.649)$ between two groups had no difference. Asoglu et al. ${ }^{47}$ recently reported the similar long-term comparing results with the mean follow-up of 92 months ( OS: $83.3 \%$ vs $75.4 \%, p=0.55$, DFS: $81.8 \%$ vs $74.7 \%, p=0.662$ ).

Up to now, although expecting that robotic TME would improve the quality of the specimen through technically more meticulous manipulation than laparoscopic TME, previous results have not provided a clear advantage in pathologic, shortterm and long-term oncologic outcomes. However, there have been no results of level I evidence, randomized controlled trial will be required. The long-term follow up results of the ROLARR trial which is the largest multicenter randomized study will be quite helpful to establish robotic rectal cancer surgery regarding oncologic surgery and selection of surgical approach.

\section{COST ANALYSIS}

In order to shift the paradigm of specific therapeutic modality in modern medicine, not only the clinical outcomes of the patients, but also the price competitiveness should be available. The main drawback of robotic surgery is relatively higher costs compared to laparoscopic surgery. In general, the overall total costs for one patient from hospital admission to discharge are consisted of operative costs (including the cost of the operation room in relation to the operative time, and laparoscopic or robotic devices, consumable instruments, etc.) and other hospitalization costs (including the cost associated with length of hospital stay; medication, nursing care, blood transfusion, radiologic exam, nutrition, fluid administration, other consumables, etc.). Table 3 demonstrates the recently published studies regarding cost analysis of robotic TME for rectal cancer comparing with the conventional approach. Almost all the studies suggested that robotic TME had definitely higher costs than laparoscopic surgery. $42,44,45,60-64$

In South Korea, Baek et al. ${ }^{60}$ reported that total hospital charges of robotic rectal surgery are larger than those of laparoscopic rectal surgery (14647 vs 9978, USD, $p=0.001$ ). The charge for anesthesia, laboratory, radiology, nursing care, and medical therapy was not different between two groups, but operative charges were significantly higher in the robotic surgery group (8849 vs 2289 , USD, $p \leq 0.001$ ). The main cost portion of the robotic surgery group was operative cost (60.3\%), whereas that of the laparoscopic surgery group was consum- 


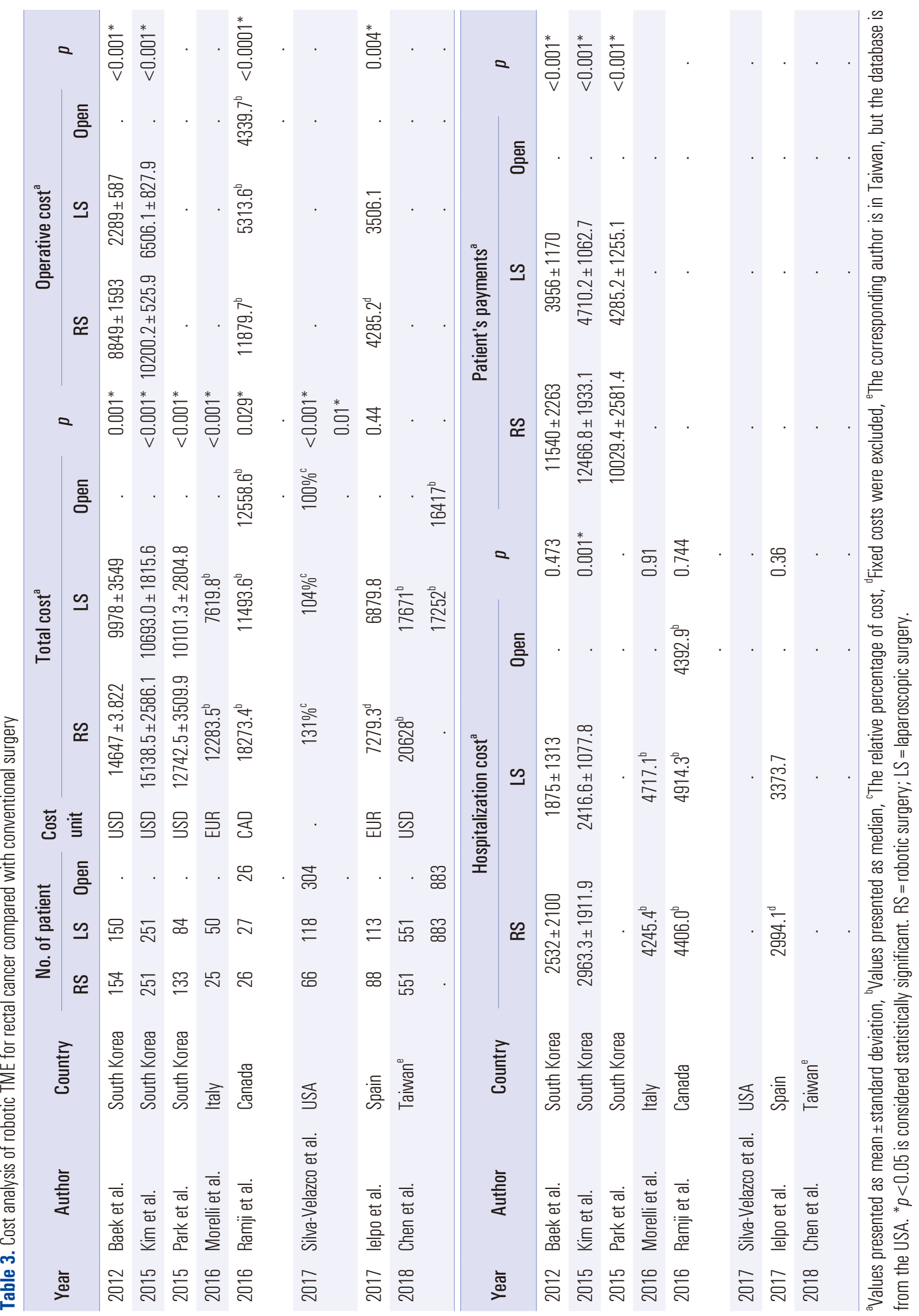


ables (33.7\%). The operative costs of robotic colorectal surgery are non-deductible in the South Korean health care system. Kim et al. ${ }^{61}$ analyzed the cost-effectiveness of robotic rectal cancer surgery focusing on short-term outcomes using propensity score-matching method. Comparing the laparoscopic group ( $\mathrm{n}=251)$, the robotic group $(\mathrm{n}=251)$ showed similar shortterm clinical outcomes, but higher costs in all categories of charges (total hospital charges, patients' payment, operative charges, anesthetic charges, and postoperative management charges). Park et al. ${ }^{42}$ reported a comparison of costs between robotic low anterior resection group and laparoscopic low anterior resection group with long-term oncologic outcomes. As mentioned above, they had similar long-term oncologic outcomes, however, the patients' payment of robotic surgery was 2.34 times higher than that of laparoscopic surgery (10029.4 vs 4285.2, USD, $p<0.001$ ), and the total cost was also higher in robotic surgery (12742.5 vs 10101.3, USD, $p<0.001$ ).

In Italy, Morelli et al. ${ }^{62}$ reported a single surgeon's initial 50 robotic rectal resection experience focusing on cost analysis according to the learning curve using the CUSUM method comparing with laparoscopic TME. They divided the costs into two categories which are fixed costs (costs related to robotic equipment or laparoscopic device), and variable costs (costs related to disposable instruments, operating room personnel, and length of stay). Based on the CUSUM method, the robotic TME group was divided into three phases (Rob1: 1 19, Rob2: 20 40, Rob3: 41 50) and there was a statistical change in the operative time of each phase. Total costs were significantly higher in the robotic TME group (12283.5 vs 7619.8, EUR, $p<0.001$ ), and variable costs were also higher in the robotic TME group comparing with the laparoscopic TME group (10614.6 vs 7585.4, EUR, $p<0.001$ ). Costs were higher for Robl comparing with Rob3 $(p<0.009)$, and it may be reflected that the reduction of overall costs was caused by the reduction of operative time with an increase of robotic experience. Excluding fixed costs, there was no significant difference in variable costs between the Rob3 group and the laparoscopic TME group $(p=0.084)$. According to this article, however, total costs were still higher in the robotic group even if the surgeon reaches the experienced phase of robotic TME $(p<0.001)$.

In Canada, Ramji et al. ${ }^{44}$ compared the clinical and economic outcomes among three approaches of rectal cancer surgery (open, laparoscopic, and robotic) in a publicly funded healthcare system. There was no statistical difference for total costs and operative costs between open and laparoscopic method, whereas, robotic surgery added approximately 6000 CAD to the median costs of each operation, increasing the average cost of stay for a patient by 1.5 times with similar clinical outcomes (Operative costs: open vs laparoscopic vs robotic, 4339.63 vs 5313.59 vs 11879.66 , CAD, $p<0.001)$. Silva-Velazco et $a l^{45}$ from the United States also reported a comparison of the clinical and cost analysis of proctectomy in patients with rectal cancer by open, laparoscopic, and robotic surgery. The total median cost of all hospitalizations per patient, the robotic group required significantly higher costs $(p<0.001)$. This finding was also detected when comparing the robotic group with an open group $(p<0.001)$ or a laparoscopic group $(p<0.001)$ respectively, while there was no difference in the open group compared to the laparoscopic group $(p=0.18)$. When the median total cost for open surgery was accounted for $100 \%$, the median total cost for the laparoscopic group was $104 \%$, and that of the robotic group was $131 \%$.

In Spain, Ielpo et al. ${ }^{63}$ reported a comparative study of clinical outcomes and costs for robotic versus laparoscopic surgery for rectal cancer. The mean operative costs were significantly higher for the robotic group (4285.16 vs 3506.11, EUR, $p=0.04$ ), but, the mean overall costs were similar in both groups (7279.31 vs 6879.80 , EUR, $p=0.44$ ). The mean hospitalization costs of the robotic group were $3383.71 \mathrm{EUR}$, and that of the laparoscopic group was 2994.14 EUR ( $p=0.63)$. However, since this study did not include fixed costs for robotic surgery (acquisition or maintenance of the robotic device), different results could be derived.

There was a largely populated retrospective analysis using the Nationwide Inpatient Sample database in the United States. ${ }^{64}$ After propensity score matching, the study included 883 matched patients each in the open and laparoscopic group, and 551 matched patients each in the laparoscopic and robotic group. Although the $\mathrm{p}$ value was not demonstrated, the robotic group had a higher median total cost comparing with the laparoscopic group (20628 vs 17671, USD). For further analysis, using odd ratio, the robotic group had a significantly higher cost than laparoscopic group (odds ratio 1.42, 95\% confidence index 1.13 1.79), but no benefit over laparoscopic surgery in terms of mortality and morbidity.

In summary, almost all studies suggested that robotic TME showed higher cost comparing with laparoscopic TME while the overall clinical outcomes were similar. After the learning curve for robotic TME, the operative costs could be reduced, but the total costs including fixed costs were still higher because of the expensive purchasing charge for the robotic system. Because of a majority of published studies regarding cost analysis for robotic TME is retrospective study, large populated prospective randomized studies on the cost-effectiveness of robotic surgery may be warranted.

\section{CONCLUSIONS}

Robotic surgery for rectal cancer is not only feasible and safe but also has various potential benefits especially surgeon- 
centered technical advantages compared to the conventional laparoscopic rectal surgery. Robotic system is considered as one of useful options when technical demanding procedures including TME in narrow pelvis, lateral pelvic nerve dissection, or intersphincteric resection are needed. However, robotic rectal surgery showed significant higher costs than laparoscopic surgery with similar overall clinical outcomes. The overall costs are higher in robotic surgery than the laparoscopic approach, especially it is account for manifestly expensive operative costs. Therefore, although robotic rectal surgery has several benefits, it is not enough to be a costeffective approach in the field of minimally invasive surgery in the present time. Because of the price of robotic equipment is mainly high, it may lead to different results in the future. Positive competition of industries in correlation with technological development may gradually reduce the price of the robotic system, and it will be helpful to increase the costeffectiveness of robotic rectal surgery with acceptable results of large populated prospective randomized studies.

\section{ORCID}

Youngbae Jeon, https://orcid.org/0000-0003-1322-9536

Eun Jung Park, https://orcid.org/0000-0002-4559-2690

Seung Hyuk Baik, https://orcid.org/0000-0003-4183-2332

\section{AUTHORS' CONTRIBUTIONS}

Conceptualization: SHB. Formal analysis: YBJ. Methodology: EJP, YBJ. Writing-original draft: YBJ. Writing-review and editing: YBJ, EJP, SHB.

\section{CONFLICT OF INTEREST}

None.

\section{FUNDING}

This research was supported by the Basic Science Research Program through the National Research Foundation of Korea (NRF) funded by the Ministry of Science and ICT (NRF2017R1A2B2011520).

\section{ACKNOWLEDGMENTS}

The authors would like to thank Ms. MiSun Park for the English editing of this paper.

\section{REFERENCES}

1) Zelhart M, Kaiser AM. Robotic versus laparoscopic versus open colorectal surgery: towards defining criteria to the right choice. Surg Endosc 2018;32:24-38.

2) Clinical Outcomes of Surgical Therapy Study G, Nelson H, Sargent DJ, et al. A comparison of laparoscopically assisted and open colectomy for colon cancer. N Engl J Med 2004;350:2050-2059.

3) Lacy AM, García-Valdecasas JC, Delgado S, et al. Laparoscopyassisted colectomy versus open colectomy for treatment of nonmetastatic colon cancer: a randomised trial. Lancet 2002;359:22242229.

4) Leung KL, Kwok SPY, Lam SCW, et al. Laparoscopic resection of rectosigmoid carcinoma: prospective randomised trial. Lancet 2004;363:1187-1192.

5) Isik O, Gorgun E. How Has the Robot Contributed to Colon Cancer Surgery? Clin Colon Rectal Surg 2015;28:220-227.

6) Zhang X, Wei Z, Bie M, Peng X, Chen C. Robot-assisted versus laparoscopic-assisted surgery for colorectal cancer: a meta-analysis. Surg Endosc 2016;30:5601-5614.

7) Leal Ghezzi T, Campos Corleta O. 30 Years of Robotic Surgery. World J Surg 2016;40:2550-2557.

8) Hanly EJ, Talamini MA. Robotic abdominal surgery. Am J Surg 2004;188:19S-26S.

9) Antoniou SA, Antoniou GA, Koch OO, Pointner R, Granderath FA. Robot-assisted laparoscopic surgery of the colon and rectum. Surg Endosc 2012;26:1-11.

10) Himpens J, Leman G, Cadiere GB. Telesurgical laparoscopic cholecystectomy. Surg Endosc 1998;12:1091-1091.

11) Hashizume M, Shimada M, Tomikawa M, et al. Early experiences of endoscopic procedures in general surgery assisted by a computer-enhanced surgical system. Surg Endosc 2002;16:1187-1191.

12) Weber PA, Merola S, Wasielewski A, Ballantyne GH. Teleroboticassisted laparoscopic right and sigmoid colectomies for benign disease. Dis Colon Rectum 2002;45:1689-1696.

13) Pigazzi A, Ellenhorn JDI, Ballantyne GH, Paz IB. Robotic-assisted laparoscopic low anterior resection with total mesorectal excision for rectal cancer. Surg Endosc 2006;20:1521-1525.

14) Baik SH, Lee WJ, Rha KH, et al. Robotic total mesorectal excision for rectal cancer using four robotic arms. Surg Endosc 2008;22: 792-797.

15) Kulaylat AS, Mirkin KA, Puleo FJ, Hollenbeak CS, Messaris E. Robotic versus standard laparoscopic elective colectomy: where are the benefits? J Surg Res 2018;224:72-78.

16) Baek SJ, Kim CH, Cho MS, et al. Robotic surgery for rectal cancer can overcome difficulties associated with pelvic anatomy. Surg Endosc 2015;29:1419-1424.

17) Kim N-K, Kang J. Optimal Total Mesorectal Excision for Rectal Cancer: the Role of Robotic Surgery from an Expert's View. J Korean Soc Coloproctol 2010;26:377-387. 
18) Park SY, Choi G-S, Park JS, Kim HJ, Ryuk J-P, Yun S-H. Urinary and erectile function in men after total mesorectal excision by laparoscopic or robot-assisted methods for the treatment of rectal cancer: a case-matched comparison. World J Surg 2014;38:18341842.

19) Morelli L,Ceccarelli C, Di Franco G, et al. Sexual and urinary functions after robot-assisted versus pure laparoscopic total mesorectal excision for rectal cancer. Int J Colorectal Dis 2016;31:913915.

20) Kim NK, Kim YW, Cho MS. Total mesorectal excision for rectal cancer with emphasis on pelvic autonomic nerve preservation: Expert technical tips for robotic surgery. Surg Oncol 2015;24:172180.

21) Leong QM, Son DN, Cho JS, et al. Robot-assisted intersphincteric resection for low rectal cancer: technique and short-term outcome for 29 consecutive patients. Surg Endosc 2011;25:2987-2992.

22) Kim JC, Lee JL, Alotaibi AM, Yoon YS, Kim CW, Park IJ. Robotassisted intersphincteric resection facilitates an efficient sphinctersaving in patients with low rectal cancer. Int J Colorectal Dis 2017; 32:1137-1145.

23) Kagawa H, Kinugasa Y, Shiomi A, et al. Robotic-assisted lateral lymph node dissection for lower rectal cancer: short-term outcomes in 50 consecutive patients. Surg Endosc 2015;29:995-1000.

24) Casillas MA, Jr., Leichtle SW, Wahl WL, et al. Improved perioperative and short-term outcomes of robotic versus conventional laparoscopic colorectal operations. Am J Surg 2014;208:33-40.

25) Bhama AR, Obias V, Welch KB, Vandewarker JF, Cleary RK. A comparison of laparoscopic androbotic colorectal surgery outcomes using the American College of Surgeons National Surgical Quality Improvement Program (ACS NSQIP) database. Surg Endosc 2016;30:1576-1584.

26) Enayati N, De Momi E, Ferrigno G. Haptics in Robot-Assisted Surgery: Challenges and Benefits. IEEE Rev Biomed Eng 2016;9: 49-65.

27) Lim $\mathrm{S}-\mathrm{C}$, Lee $\mathrm{H}-\mathrm{K}$, Park J. Role of combined tactile and kinesthetic feedback in minimally invasive surgery. Int J Med Robot 2015;11:360-374.

28) Park IJ, Choi G-S, Lim KH, Kang BM, Jun SH. Multidimensional analysis of the learning curve for laparoscopic resection in rectal cancer. J Gastrointest Surg 2009;13:275-281.

29) Miskovic D, Ni M, Wyles SM, Tekkis P, Hanna GB. Learning curve and case selection in laparoscopic colorectal surgery: systematic reviewand international multicenter analysis of 4852 cases. Dis Colon Rectum 2012;55:1300-1310.

30) Bokhari MB, Patel CB, Ramos-Valadez DI, Ragupathi M, Haas EM. Learning curve for robotic-assisted laparoscopic colorectal surgery. Surg Endosc 2011;25:855-860.

31) Jiménez-Rodríguez RM, Díaz-Pavón JM, de la Portilla de Juan F, Prendes-Sillero E, Dussort HC, Padillo J. Learning curve for robotic-assisted laparoscopic rectal cancer surgery. Int J Colorectal
Dis 2013;28:815-821.

32) Sng KK, Hara M, Shin J-W, Yoo B-E, Yang K-S, Kim S-H. The multiphasic learning curve for robot-assisted rectal surgery. Surg Endosc 2013;27:3297-3307.

33) Park EJ, Kim CW, Cho MS, et al. Multidimensional analyses of the learning curve of robotic low anterior resection for rectal cancer: 3-phase learning process comparison. Surg Endosc 2014;28: 2821-2831.

34) Yamaguchi T, Kinugasa Y, Shiomi A, et al. Learning curve for robotic-assisted surgery for rectal cancer: use of the cumulative sum method. Surg Endosc 2015;29:1679-1685.

35) Foo CC, Law WL. The Learning Curve of Robotic-Assisted Low Rectal Resection of a Novice Rectal Surgeon. World J Surg 2016; 40:456-462.

36) Schlachta CM, Mamazza J, Seshadri PA, Cadeddu M, Gregoire R, Poulin EC. Defining a learning curve for laparoscopic colorectal resections. Dis Colon Rectum 2001;44:217-222.

37) Son G-M, Kim J-G, Lee J-C, et al. Multidimensional analysis of the learning curve for laparoscopic rectal cancer surgery. J Laparoendosc Adv Surg Tech A 2010;20:609-617.

38) Park EJ, Kim CW, Cho MS, et al. Is the learning curve of robotic low anterior resection shorter than laparoscopic low anterior resection for rectal cancer?: a comparative analysis of clinicopathologic outcomes between robotic and laparoscopic surgeries. Medicine (Baltimore) 2014;93:e109-e109.

39) Shaw DD, Wright M, Taylor L, et al. Robotic Colorectal Surgery Learning Curve and Case Complexity. J Laparoendosc Adv Surg Tech A 2018;28:1163-1168.

40) Baik SH, Ko YT, Kang CM, et al. Robotic tumor-specific mesorectal excision of rectal cancer: short-term outcome of a pilot randomized trial. Surg Endosc 2008;22:1601-1608.

41) Patriti A, Ceccarelli G, Bartoli A, Spaziani A, Biancafarina A, Casciola L. Short- and medium-term outcome of robot-assisted and traditional laparoscopic rectal resection. JSLS 2009;13:176-183.

42) Park EJ, Cho MS, Baek SJ, et al. Long-term oncologic outcomes of robotic low anterior resection for rectal cancer: a comparative study with laparoscopic surgery. Ann Surg 2015;261:129-137.

43) Cho MS, Baek SJ, Hur H, et al. Short and long-term outcomes of robotic versus laparoscopic total mesorectal excision for rectal cancer: a case-matched retrospective study. Medicine (Baltimore) 2015;94:e522-e522.

44) Ramji KM, Cleghorn MC, Josse JM, et al. Comparison of clinical and economic outcomes between robotic, laparoscopic, and open rectal cancer surgery: early experience at a tertiary care center. Surg Endosc 2016;30:1337-1343.

45) Silva-Velazco J, Dietz DW, Stocchi L, et al. Considering Value in Rectal Cancer Surgery: An Analysis of Costs and Outcomes Based on the Open, Laparoscopic, and Robotic Approach for Proctectomy. Ann Surg 2017;265:960-968.

46) Kim MJ, Park SC, Park JW, et al. Robot-assisted Versus Lapa- 
roscopic Surgery for Rectal Cancer: A Phase II Open Label Prospective Randomized Controlled Trial. Ann Surg 2018;267:243251.

47) Asoglu O, Tokmak H, Bakir B, et al. Robotic versus laparoscopic sphincter-saving total mesorectal excision for mid or low rectal cancer in male patients after neoadjuvant chemoradiation therapy: comparison of long-term outcomes. J Robot Surg 2019 Jul 16 [Epub]. DOI: 10.1007/s11701-019-01001-5.

48) Polat F, Willems LH, Dogan K, Rosman C. The oncological and surgical safety of robot-assisted surgery in colorectal cancer: outcomes of a longitudinal prospective cohort study. Surg Endosc 2019;33:3644-3655.

49) Baik SH, Kwon HY, Kim JS, et al. Robotic versus laparoscopic low anterior resection of rectal cancer: short-term outcome of a prospective comparative study. Ann Surg Oncol 2009;16:14801487.

50) Jayne D, Pigazzi A, Marshall H, et al. Effect of Robotic-Assisted vs Conventional Laparoscopic Surgery on Risk of Conversion to Open Laparotomy Among Patients Undergoing Resection for Rectal Cancer: The ROLARR Randomized Clinical Trial. JAMA 2017;318:1569-1580.

51) Broholm M, Pommergaard HC, Gögenür I. Possible benefits of robot-assisted rectal cancer surgery regarding urological and sexual dysfunction: a systematic review and meta-analysis. Colorectal Dis 2015;17:375-381.

52) Wang G, Wang Z, Jiang Z, Liu J, Zhao J, Li J. Male urinary and sexual function after robotic pelvic autonomic nerve-preserving surgery for rectal cancer. Int J Med Robot 2017;13:e1725.

53) Baek J-H, McKenzie S, Garcia-Aguilar J, Pigazzi A. Oncologic outcomes of robotic-assisted total mesorectal excision for the treatment of rectal cancer. Ann Surg 2010;251:882-886.

54) Pai A, Marecik SJ, Park JJ, Melich G, Sulo S, Prasad LM. Oncologic and Clinicopathologic Outcomes of Robot-Assisted Total Mesorectal Excision for Rectal Cancer. Dis Colon Rectum 2015; 58:659-667.
55) Hellan M, Anderson C, Ellenhorn JDI, Paz B, Pigazzi A. Shortterm outcomes after robotic-assisted total mesorectal excision for rectal cancer. Ann Surg Oncol 2007;14:3168-3173.

56) Choi DJ, Kim SH, Lee PJM, Kim J, Woo SU. Single-stage totallyrobotic dissection for rectal cancer surgery: technique and shortterm outcome in 50 consecutive patients. Dis Colon Rectum 2009; 52:1824-1830.

57) Pigazzi A, Luca F, Patriti A, et al. Multicentric study on robotic tumor-specific mesorectal excision for the treatment of rectal cancer. Ann Surg Oncol 2010;17:1614-1620.

58) Baik SH, Kim NK, Lim DR, Hur H, Min BS, Lee KY. Oncologic outcomes and perioperative clinicopathologic results after robotassisted tumor-specific mesorectal excision for rectal cancer. Ann Surg Oncol 2013;20:2625-2632.

59) Feroci F, Vannucchi A, Bianchi PP, et al. Total mesorectal excision for mid and low rectal cancer: Laparoscopic vs robotic surgery. World J Gastroenterol 2016;22:3602-3610.

60) Baek S-J, Kim S-H, Cho J-S, Shin J-W, Kim J. Robotic versus conventional laparoscopic surgery for rectal cancer: a cost analysis from a single institute in Korea. World J Surg 2012;36:2722-2729.

61) Kim CW, Baik SH, Roh YH, et al. Cost-effectiveness of robotic surgery for rectal cancer focusing on short-term outcomes: a propensity score-matching analysis. Medicine (Baltimore) 2015;94: e823-e823.

62) Morelli L, Guadagni S, Lorenzoni V, et al. Robot-assisted versus laparoscopic rectal resection for cancer in a single surgeon's experience: a cost analysis covering the initial 50 robotic cases with the da Vinci Si. Int J Colorectal Dis 2016;31:1639-1648.

63) Ielpo B, Duran H, Diaz E, et al. Robotic versus laparoscopic surgery for rectal cancer: a comparative study of clinical outcomes and costs. Int J Colorectal Dis 2017;32:1423-1429.

64) Chen $\mathrm{S}-\mathrm{T}$, Wu M-C, Hsu T-C, et al. Comparison of outcome and cost among open, laparoscopic, and robotic surgical treatments for rectal cancer: A propensity score matched analysis of nationwide inpatient sample data. J Surg Oncol 2018;117:497-505. 